\title{
Evaluation of the Association of Parent's Oral Health Knowledge and Development of Dental Caries in their Children
}

\author{
Suma G* and Anisha P \\ Department of Paediatric and Preventive Dentistry, VS \\ Dental College, India \\ *Correspondling author: Suma G, Department of \\ Paediatric and Preventive Dentistry, V.S. Dental College, \\ Bangalore, India
}

Received: August 31, 2017; Accepted: October 06, 2017; Published: October 30, 2017

\begin{abstract}
Aim: To evaluate the association of oral health knowledge of parents and development of dental caries in their children.

Materials and Methods: 100 children aged between 4-12 yrs were examined for dental caries using WHO criteria. Educational level and oral health knowledge of parents was measured by a self structured questionnaire. The questionnaires for parents were handed over to the children who carried it to their home. Those questionnaires were filled by parents and children brought them back to the school and were collected from the school, the next day. The acquired data was tabulated and subjected for statistical analysis.
\end{abstract}

Results: The overall mean $\mathrm{dmft}$ score was 1.62(0.51). The mean dmft in boys was $1.46(0.42)$ and in girls it was $1.84(0.58)$. As the age of the children increased from 4 to 12 years the dmft value was also increased. Father's education, child order in the family, no. of siblings, parent's brushing habits, parent's knowledge about fluorides, higher snacking frequency all these factors were significantly associated with dental caries in their children.

Conclusion: Parents knowledge of oral hygiene had effect on their children oral health. So adequate dental health education for parents is necessary regarding the influence of their dental health habits on their children's oral health.

Keywords: Dental caries; parent's oral health knowledge; dmft; Questionnaire

\section{Introduction}

Dental caries refers to the localized destruction of susceptible dental hard tissues by acidic by-products from the bacterial fermentation of dietary carbohydrates. It is a chronic disease that progresses slowly in most of the people which results from an ecological imbalance in the equilibrium between tooth minerals and oral bio-films (plaque) [1]. Dental caries is considered a major public health problem globally due to its high prevalence and significant social impact. World Health Organization reports 60$90 \%$ of schoolchildren worldwide have experienced caries, with the disease being most prevalent in Asian and Latin American countries [2]. It's very high morbidity potential has brought this disease into the main focus of the dental health profession. There is practically no geographic area in the world whose inhabitant does not exhibit some evidence of dental caries. It affects both the sexes, all races, all socioeconomic status and all age groups [3].

Dental caries is a common disease in children. Children's body weight and growth is significantly affected due to untreated dental caries, also the quality of life in preschool children. Caries experience in early childhood has been linked to caries experience in the permanent dentition in several studies [4]. Dental caries that is left untreated can affect children's quality of life as the untreated caries cause discomfort, pain, dental sepsis which may result in loss of school days [5].
The environmental factors have a major influence on caries development and are well known. The mother as well as the entire family plays a key part in children's environment influencing the development and establishment of oral health behaviors. There is a significant growth in literature related to the association between caries experience in children and characteristics of the family, parental oral health behaviors and lifestyle. ${ }^{4}$ Routines like tooth brushing habits, dietary habits, and food choices of parents are directly associated with those of their children. Dental care professionals accept that the efforts intended to improve parental oral health behaviors could result in enhanced health in their children. However many factors are identified which can indirectly influence the parent's health habits and in result their children's health. Some of these factors include parent's education, occupation, age, current knowledge, attitude, and behavior relating to health. The importance of a parent's knowledge on health including oral health cannot be overemphasized because most of their decisions with regard to the health of their children will be based on their knowledge [6].

Children with poor oral health habits are more likely to develop dental caries when compared with those who have favorable habits. Moreover, many other aspects like low socioeconomic status of the family and parents poor oral health habits contribute to the development of dental caries. In addition to that, factors such as gender and multiple levels of influence including time or
Austin J Dent - Volume 4 Issue 7 - 2017

ISSN : 2381-9189 | www.austinpublishing group.com

Suma et al. () All rights are reserved
Citation: Suma G and Anisha P. Evaluation of the Association of Parent's Oral Health Knowledge and Development of Dental Caries in their Children. Austin J Dent. 2017; 4(7): 1092. 


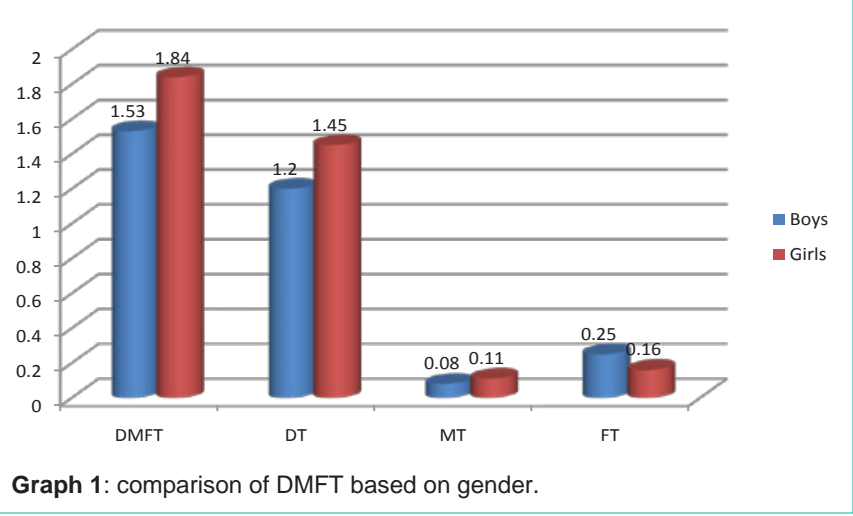

developmental dimensions have been observed [7].

It is an emerging fact that health promotion and education efforts to influence preventive behaviors must be targeted to specific audiences. Thus the oral care access for the children can be improved by assessing the oral health knowledge of their mothers who are the primary care taker of their children [6]. The purpose of this study was to assess the knowledge regarding parental influence, further specifically family characteristics, oral health behaviors and lifestyle on caries development in children.

\section{Materials and Methods}

The study was conducted at Sajjan rao vidya Samasthe School, South Bangalore. Healthy patients were selected for the study from children attending school. 100 children aged between 4-12 yrs were examined for dental caries using WHO criteria. The head master of the school was contacted and consent was obtained for participation in study. The study tools comprised of self structured, close ended questions to assess parental oral health knowledge. The questionnaires for parents were handed over to the children who carried it to their home. Those questionnaires were filled by parents and children brought them back to the school and were collected from the school, the next day.

The oral assessment of every child was done by seating each subject on a chair in a good day light using required instruments. The basic oral examination instruments like plane mouth mirror, with blunt probe and dental lamp for the detection of dental caries were used. Caries were recorded as when a lesion is present on enamel in pits and fissures or on smooth surface of teeth. Oral examination was done by single operator to detect the presence of dental caries, missing (extracted or congenital) and filled teeth. Those teeth which

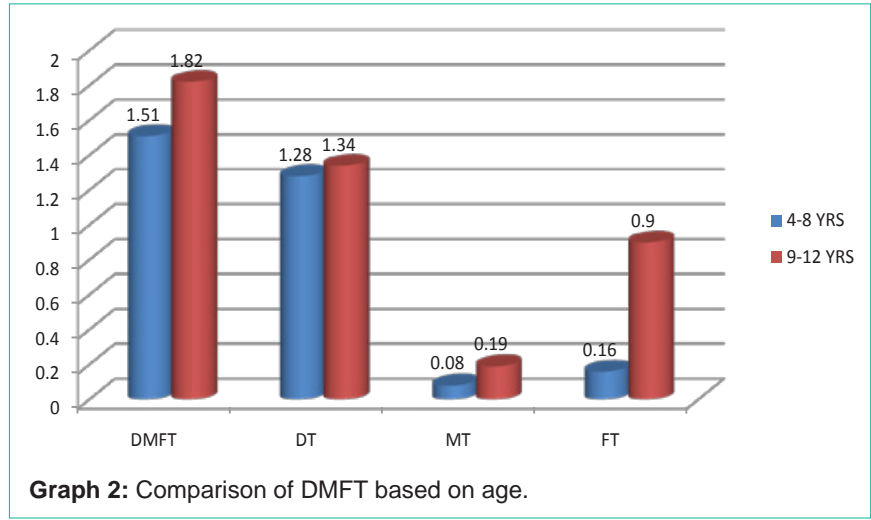

are filled by dental fillings on permanent teeth and those are carious lesion present on the tooth surface are considered as the carious lesion, for the record, of $\mathrm{dmft}$.

Collected data was subjected to descriptive analysis using the SPSS 12.0 version. Statistical analysis used is independent t test and chi square test. Risk factor association with dental caries was investigated using a stepwise logistic regression analysis with P-values $<0.05$ considered significant.

\section{Results}

The study was conducted to find an association of parent's oral health knowledge and development of dental caries in their children. Of the 100 students examined, 38 were boys and 62 were girls. The frequency of age distribution was 4-8(41\%) year age, 8-12 (59\%) year age.

The overall mean DMFT score was $1.62(0.51)$, scores of dt, mt, and $\mathrm{ft}$ components were $1.32(0.33), 0.09(0.28), 0.21(0.32)$ respectively. The mean DMFT in boys was 1.46(0.42) and in girls it was 1.84(0.58) (Graph 1). The DMFT value by age stratification showed that DMFT value was $1.51(0.44)$ in $4-8$ years old and $1.72(0.49)$ in $8-12$ years old respectively (Graph 2). The study showed that as the age of the children increased from 4 to 12 years the DMFT value was also increased (Table 1).

It was found that only father's level of education to be significantly associated with the dental caries status of children $(\mathrm{p}<0.05)$ (Table 2). No significant association was seen with the mother's level of education. Family status from pregnancy to age 4 was significantly associated with dental caries status of their children. The child order in the family was significantly associated with $\mathrm{dmft}$ score. Of all the

Table 1: Comparison of DMFT based on Gender and Age.

\begin{tabular}{|c|c|c|c|c|c|c|c|c|c|c|c|}
\hline $\mathrm{S} / \mathrm{N}$ & Variables & Categories & No(\%) & DMFT Mean(SD) & DMFT(\%) & DT & DT(\%) & MT & MT(\%) & FT & FT(\%) \\
\hline \multirow{3}{*}{1} & \multirow{3}{*}{ Gender } & Boys & $38(38)$ & $1.46(0.42)$ & 54.9 & $1.20(0.28)$ & 33.1 & $0.08(0.11)$ & 8.5 & $0.25(0.29)$ & 12.4 \\
\hline & & Girls & $62(62)$ & $1.84(0.58)$ & 71.6 & $1.46(0.42)$ & 62.3 & $0.11(0.18)$ & 2.5 & $0.16(0.04)$ & 4.8 \\
\hline & & P-value(t- test) & & $0.0013^{*}$ & & $0.0020^{*}$ & & 0.387 & & $0.0133^{*}$ & \\
\hline \multirow{3}{*}{2} & \multirow{3}{*}{ Age } & $4-8$ & $41(41)$ & $1.51(0.44)$ & 59.2 & $1.28(0.28)$ & 44.1 & $0.15(0.23)$ & 4.5 & $0.26(0.11)$ & 10.4 \\
\hline & & $8-12$ & $59(59)$ & $1.72(0.49)$ & 66.3 & $1.34(0.34)$ & 52.2 & $0.06(0.02)$ & 7.6 & $0.19(0.14)$ & 6.1 \\
\hline & & $P$ value(t-test) & & $0.030^{*}$ & & 0.515 & & $0.0035^{*}$ & & 0.206 & \\
\hline 3 & Total & & 100 & $1.62(0.51)$ & 62.8 & $1.32(0.33)$ & 48.1 & $0.09(0.28)$ & 6.2 & $0.21(0.32)$ & 8.7 \\
\hline
\end{tabular}

*Independent t-test statistics 
Table 2: Comparison of DMFT based on questionnaire.

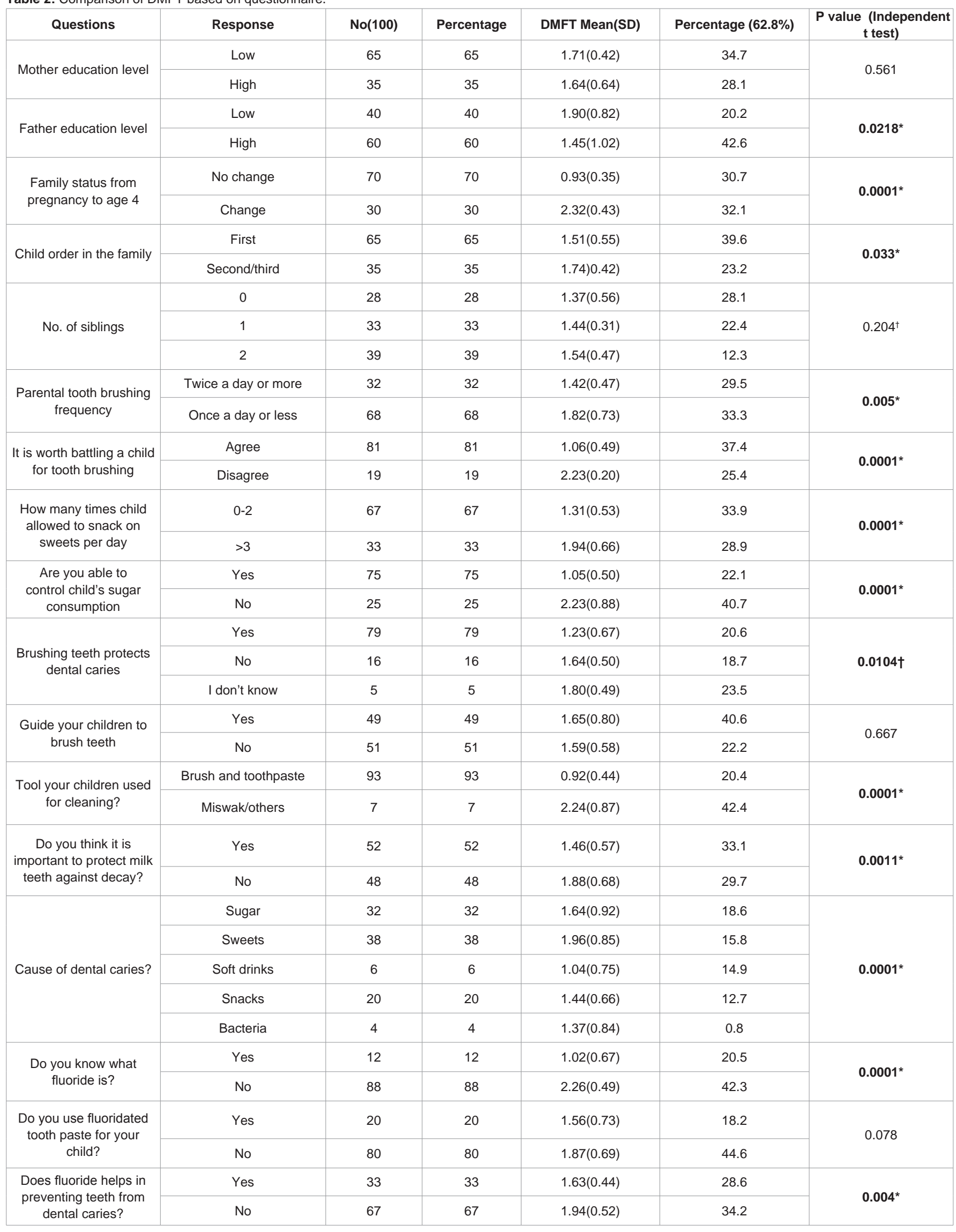




\begin{tabular}{|c|c|c|c|c|c|}
\hline \multirow{2}{*}{ What is dental plaque? } & Food remaining on teeth & 16 & 16 & $1.45(0.49)$ & 12.6 \\
\cline { 2 - 5 } & Stains & 20 & 20 & $1.86(0.69)$ & 24.2 \\
\cline { 2 - 5 } & Don't know & 64 & 64 & $1.63(0.45)$ & 26 \\
\hline \multirow{2}{*}{$\begin{array}{c}\text { Brushing frequency of } \\
\text { child }\end{array}$} & Once daily & 72 & 72 & $1.86(0.40)$ & 37.5 \\
\cline { 2 - 5 } & Twice and more. & 28 & 28 & $1.43(0.52)$ & 25.3 \\
\hline
\end{tabular}

*Independent t -test statistics

${ }^{\dagger}$ Anova statistics

Table 3: logistic regression with DMFT s dependent variable with other independent variables.

\begin{tabular}{|c|c|c|c|c|}
\hline Questions & Response & Odds ratio & Confidence interval & P value \\
\hline \multirow{2}{*}{ Mother education level } & Low & 1 & & \multirow{2}{*}{0.662} \\
\hline & High & 0.79 & $0.58-1.46$ & \\
\hline \multirow{2}{*}{ Father education level } & Low & 1 & & \multirow{2}{*}{$0.024^{*}$} \\
\hline & High & 0.66 & $0.41-0.89$ & \\
\hline \multirow{2}{*}{ Family status from pregnancy to age 4} & No change & 1 & & \multirow{2}{*}{$0.001^{*}$} \\
\hline & Change & 1.24 & $1.12-1.43$ & \\
\hline \multirow{2}{*}{ Child order in the family } & First & 1 & & \multirow{2}{*}{$0.0001^{*}$} \\
\hline & Second/third & 1.54 & $1.22-1.98$ & \\
\hline \multirow{4}{*}{ No. of siblings } & 0 & 1 & & \multirow{4}{*}{$0.006^{*}$} \\
\hline & & & & \\
\hline & 1 & 1.23 & $1.14-1.67$ & \\
\hline & 2 & 1.66 & $1.43-1.89$ & \\
\hline \multirow{2}{*}{ Parental tooth brushing frequency } & Twice a day or more & 1 & & \\
\hline & Once a day or less & 1.81 & $1.23-2.01$ & $0.0001^{*}$ \\
\hline \multirow{2}{*}{ It is worth battling a child for tooth brushing } & Agree & 1 & & \multirow{2}{*}{$0.0001^{*}$} \\
\hline & Disagree & 1.92 & $1.42-2.22$ & \\
\hline \multirow{2}{*}{ How many times child allowed to snack on sweets per day } & $0-2$ & 1 & & \multirow{2}{*}{$0.0001^{*}$} \\
\hline & $>3$ & 1.74 & $1.49-1.89$ & \\
\hline \multirow{2}{*}{ Are you able to control child's sugar consumption } & Yes & 1 & & \multirow{2}{*}{$0.0001^{*}$} \\
\hline & No & 1.55 & $1.11-1.57$ & \\
\hline \multirow{3}{*}{ Brushing teeth protects dental caries } & Yes & 1 & & \multirow{3}{*}{$0.0001^{*}$} \\
\hline & No & 1.34 & $1.24-1.68$ & \\
\hline & I don't know & 1.89 & $1.44-1.99$ & \\
\hline \multirow{2}{*}{ Guide your children to brush teeth } & Yes & 1 & & \multirow{2}{*}{0.763} \\
\hline & No & 1.23 & $0.88-1.34$ & \\
\hline \multirow{2}{*}{ Tool your children used for cleaning? } & Brush and toothpaste & 1 & & \multirow{2}{*}{$0.0001^{*}$} \\
\hline & Miswak/others & 1.56 & $1.45-1.76$ & \\
\hline \multirow{2}{*}{ Do you think it is important to protect milk teeth against decay? } & Yes & 1 & & \multirow{2}{*}{$0.0001^{*}$} \\
\hline & No & 1.67 & $1.46-1.88$ & \\
\hline \multirow{2}{*}{ Do you know what fluoride is? } & Yes & 1 & & \multirow[b]{2}{*}{$0.0001^{*}$} \\
\hline & No & 2.01 & $1.65-2.13$ & \\
\hline \multirow{2}{*}{ Do you use fluoridated tooth paste for your child? } & Yes & 1 & & \multirow{2}{*}{0.065} \\
\hline & No & 1.23 & $0.96-1.45$ & \\
\hline Denc fluoride holnc in nreventing toeth from dental carioc? & Yes & 1 & & 0 0n01* * \\
\hline 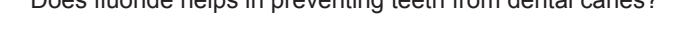 & No & 1.67 & $1.23-1.87$ & 0.0001 \\
\hline
\end{tabular}




\begin{tabular}{|c|c|c|c|c|}
\hline \multirow{2}{*}{ Brushing frequency of child } & Once daily & 1 & & \multirow{2}{*}{$0.0001^{*}$} \\
\hline & Twice and more. & 0.63 & $0.44-0.84$ & \\
\hline
\end{tabular}

children enrolled, 72 had siblings. However, a higher number of siblings were also found to be significantly associated with higher caries status (Table 3). Parents who brush their teeth twice a day or more was significantly associated with a reduced caries status in their children. Higher snacking frequency was found to be significantly associated with increased caries status in children. Parents who were not able to control child's sugar consumption were significantly associated with higher $\mathrm{dmft}$ score in their children. When asked from parents if brushing teeth prevents caries, $79 \%$ answered 'yes' as a response. Regarding the factors leading to dental caries, $4 \%$ stated bacteria, $32 \%$ chose sugar, $38 \%$ stated sweets, $6 \%$ chose soft drinks, and $20 \%$ highlighted frequent snacking as causative factors.

It has also been observed that $93 \%$ parents used tooth brush and tooth paste for cleaning of their children's teeth whereas $7 \%$ used Miswak for cleaning teeth. The odds of dental caries in children were higher if their parents answered that fluoride does not prevent dental caries. The odds of dental caries were higher in children not using fluoridated tooth paste. Higher $\mathrm{dmft}$ was seen in those children whose parents said that fluoride had no effect on preventing teeth from dental caries.

In response to the question asked from parents regarding the knowledge of plaque, $16 \%$ responded plaque as food remaining on the teeth, $20 \%$ consider plaque as stains, while $64 \%$ did not know what plaque was. Parents who insisted on their children brushing twice daily had children with lower $\mathrm{dmft}$ scores.

\section{Discussion}

Children attain majority of their knowledge through their parents. The practice of incorporating this knowledge to extend multiple skills begins at home. For teaching healthy practices to children, an understanding of 'oral health' among parents is crucial. ${ }^{8}$ Promotion of oral health and prevention of disease, along with development of good dietary and oral health lifestyle must begin early in life [9]. A study conducted in Ludhiana showed that parental attitudes toward their children's oral health were significantly associated with positive parental oral health activities [10].

The study was done to explore the association between oral health knowledge of parents and $\mathrm{dmft}$ score in their children. The mean dmft index score was 1.62(0.51) which was similar to National health survey of Pakistan (NHSP) which was 1.6 [11] and higher than the study conducted by Ali leghari [5]. Decayed component showed a high score and very negligible missing component was observed in the present study. Studies conducted in North \$ West Belfast [12] and Mysore showed maximum decayed component and very negligible filled component [13]. Decayed component which formed the key element of dmft score suggests the big unmet treatment needs. This can be attributed to the lack of oral health knowledge in parents, detrimental feeding habits and oral hygiene practices, high cost of dental treatment and restricted accessibility and availability of dental services.

The $\mathrm{dmft}$ score was higher in girls compared to boys, which can be explained by several factors. Girls have more exposure time for cariogenic oral environment as teeth erupt earlier in girls than boys. Association of girls to snacking during food preparation and the pregnancy and hormonal influences also has an effect on their oral cavity. The biochemical composition of saliva and rate of flow varies in girls and boys [14].

The more favorable oral self care of children are found in parents with high education level. In our study the father's level of education was found to be significantly associated with the dental caries experience in their children. Other two studies [15]; have found that the mother's level of education influence oral health related quality of life of their children but not the father's [16]. The differences in parental roles in those countries may be responsible for these results.

In our study children's tooth brushing behavior was significantly developed by parent's tooth brushing habits. An international study involving 17 countries confirmed this result [17]. The inability of the parents to systemize or assist their child's tooth brushing behavior was linked with the presence of dental caries in their children. According to Finlayson et al children only play with tooth brush in their mouths, and do not actually clean their teeth while learning to brush [18]. The motivation and manual dexterity to perform effective tooth brushing is less in children below 10 years of age [19]. Therefore, mothers play a key role in helping their children by teaching them favorable oral health habits. Hence, parents have an important role in helping their children to develop good oral health behaviors.

In cases where parents couldn't control the sugar consumption of their children, resulted in higher $\mathrm{dmft}$ score among them. This verdict is in agreement with the study done by Amrita Sujilana, et al. [20]. Tooth brushing was the most accepted method used by study population among the methods used for cleaning teeth, followed by Miswak. This result has the conformity with previous studies by Rafi [21] and Ronis [22]. Insufficient knowledge about the fluoride in parents also had an effect on the dental caries experience in their children.

Kay and Locker stated that, health education is helpful in raising the level of knowledge, and in changing both attitudes and beliefs [23]. WHO main concern for the improvement of oral health worldwide includes effective use of fluoride, healthy diet, nutrition and oral health of children [24]. Parents too should be educated through the programs like preventive oral care in schools and oral health educational programs intended at general public. Restriction of this study is that it was carried out in one institution only. A larger study group will be helpful to give a wider depiction of the oral health knowledge of parents.

\section{Conclusion}

Parent's knowledge of oral hygiene had effect on their children oral health. The learning process for the children starts from home. So adequate dental health education for parents is necessary regarding the influence of their dental health habits on their children's oral health. 


\section{References}

1. Khushbu Yadav, Satyam Prakash. Dental Caries: A Review. Asian Journal of Biomedical and Pharmaceutical Sciences. 2016; 6: 01-07.

2. Lonim Prasai Dixit, Ajay Shakya, Manash Shrestha, Ayush Shrestha. Dental caries prevalence, oral health knowledge and practice among indigenous Chepang school children of Nepal. BMC Oral Health. 2013; 13: 20.

3. Joyson Moses, B N Rangeeth, Deepa Gurunathan. Prevalence of Dental Caries, Socio-Economic Status and Treatment Needs among Schoo Children. Journal of Clinical and Diagnostic Research. 2011; 5:146-151.

4. Tove I, Wigen and Nina J. Wang. Parental influences on dental caries development in Preschool children. An overview with emphasis on recent Norwegian research. Norsk Epidemiologi. 2012; 22: 13-19.

5. Leghari MA, Tanwir F, Ali H. Association of dental caries and parents knowledge of oral health, A cross-sectional survey of Private Schools. J PAk Dent Assoc. 2014; 23: 19-24.

6. Folakemi Oredugba, Maarufah Agbaje, Oladipo Ayedun, Adebayo Onajole Assessment of Mothers' Oral Health Knowledge: Towards Oral Health Promotion for Infants and Children. Health. 2014; 6: 908-915.

7. Aline Rogeria Freire de Castilho AR, Mialhe FL, Barbosa TS, Puppin-Rontani RM. Influence of family environment on children's oral health: a systematic review. J Pediatr (Rio J). 2013; 89: 116-123

8. World Health Organization. Oral health surveys basic method: 4th edition, Geneva, WHO 1997: 760-871.

9. Mouradian WE, Wehr E, and Grall JJ. Disparities in Children's Oral Health and Access to Dental Care. JAMA. 2000; 284: 2625-2631.

10. Vanegas G, Milasausktene Z, Grabauskas V, and Mickeviciene A Associations between Parental Skills and Their Attitudes toward Importance to Develop Good Oral Hygiene Skills in Their Children. Medicina (Kaunas) 2009; 45: 718-723

11. Haleem A, Khan A.A. Dental caries and oral hygiene status of 12 years old school children in Pakistan. Pak J Med Res. 2001; 40: 138-142.

12. Freeman R1, Breistein B, McQueen A, Stewart M. The dental health status of five-year-old children in north and west Belfast. Community Dent Health. 1997; 14: 253-257.

13. Bennadi D, Reddy CVK, Sunitha S, Kshetrimayum N. Oral health status of 3-6 year old children and their mother's oral health related knowledge, attitude and practices in Mysore city, India. Asian Journal of Medical Sciences. 2015; 6: 66-71.
14. Lukacs JR, Largaespada LL. Explaining Sex Differences in Dental Caries Prevalence: Saliva, Hormones, and "Life-History" Aetiologies'. American Journal of human biology. 2006; 8: 540-555.

15. Pani SC, Mubaraki SA, Ahmed YT, Alturki RY, Almahfouz SF. Parental perceptions of the oral health-related quality of life of autistic children in Saudi Arabia. Spec Care Dent. 2013; 33: 8-12.

16. Vargas-Ferreira F, Piovesan C, Praetzel JR, Mendes FM, Allison PJ, Ardengh $\mathrm{TM}$. Tooth erosion with low severity does not impact child oral health-related quality of life. Caries Res. 2010; 44: 531-539.

17. Adair PM, Pine CM, Burnside G, Nicoll AD, Gillett A, Anwar S, et al. Familia and cultural perceptions and beliefs of oral hygiene and dietary practices among ethnically and socio-economically diverse groups. Community Dent Health. 2004; 21: 102-111.

18. Finlayson TL1, Siefert K, Ismail AI, Sohn W. Maternal self-efficacy and 1-5-year-old children's brushing habits. Community Dent Oral Epidemiol. 2007; 35: 272-281.

19. Grossman E1, Proskin H. A comparison of the efficacy and safety of an electric and a manual children's toothbrush. J Am Dent Assoc. 1997; 128: 469-474.

20. Pannu PK,Sujilana A. Family related factors associated with caries prevalence in the primary dentition of five-year old children. J Indian Soc Pedod Prev Dent. 2015; 33: 83-87.

21. Rafi AT, Syed Mohammed Yaseen, Zakirulla M, Nasim VS, Mohammed A Zamzami. Oral hygiene knowledge and practices among school children in a rural area of southern Saudi Arabia. Int.Journal of Contemporary Dentistry. 2012; 3: 57-62.

22. Ronis DL, Lang WP, Fraghaly MM, et al. Tooth brushing, flossing and preventive dental visits by Detroit area residents in relation to demographic and socio economic factors. J Public Health Dent 1993; 53: 138-45.

23. Kay E, Locker D. A systematic review of the effectiveness of health promotion aimed at improving oral health. Community Dent Health. 1998; 15: 132-144.

24. World Health Organization (2005) WHO Bulletin. Special Theme on Oral Health. WHO, Geneva
Austin J Dent - Volume 4 Issue 7 - 2017

ISSN : 2381-9189 | www.austinpublishing group.com

Suma et al. (C) All rights are reserved
Citation: Suma G and Anisha P. Evaluation of the Association of Parent's Oral Health Knowledge and Development of Dental Caries in their Children. Austin J Dent. 2017; 4(7): 1092. 